\title{
Endovascular repair of the ascending aorta: the last frontier?
}

\author{
Drosos Kotelis ${ }^{1}$, Johannes Kalder ${ }^{1}$, Michael J. Jacobs ${ }^{1,2}$ \\ ${ }^{1}$ European Vascular Center Aachen-Maastricht, Department of Vascular Surgery, University Hospital RWTH Aachen, Aachen, Germany; ${ }^{2}$ European \\ Vascular Center Aachen-Maastricht, Department of Vascular Surgery, Maastricht University Medical Center, Maastricht, the Netherlands \\ Correspondence to: Drosos Kotelis, MD. European Vascular Center Aachen-Maastricht, Department of Vascular Surgery, University Hospital RWTH \\ Aachen, Pauwelsstrasse 30, 52074 Aachen, Germany. Email: dkotelis@ukaachen.de.
}

Submitted Jun 03, 2016. Accepted for publication Jun 15, 2016.

doi: $10.21037 /$ jtd.2016.07.49

View this article at: http://dx.doi.org/10.21037/jtd.2016.07.49

Starting at the infrarenal portion of the aorta, endovascular aortic repair with stent-grafts has evolved to the therapy of first choice for a variety of aortic pathologies and the majority of patients (1-3). The endovascular revolution has been galloping within two decades from the infrarenal aorta towards the thoracic and thoracoabdominal aorta, and has reached the aortic arch, with branched devices now enabling total endovascular solutions $(4,5)$. The ascending aorta is anatomically the last frontier of the evolution of endovascular aortic therapies.

Especially focal lesions, such as pseudoaneurysms and penetrating aortic ulcers (PAUs) as presented in the present paper, are amendable to endovascular exclusion by stentgrafting (6). The authors have to be congratulated for treating a group of eight patients, all considered at high risk for open repair, with no mortality and $88 \%$ success (7/8 patients) in exclusion of the lesions at 1-year follow-up (6). Five of the eight patients presented with pseudoaneurysms following cannulation of the ascending aorta for cardiac surgery, meaning that the alternative would have been redo open repair, that has been shown to carry an increased risk of operative morbidity and mortality (7).

Stent-grafting of the ascending aorta [thoracic endovascular aneurysm repair (TEVAR)] is also very challenging though. Due to the curvature of the aortic arch and the hemodynamic forces in this aortic segment, TEVAR in the ascending aorta is performed under induced hypotension, mostly by means of overdrive pacing in order to achieve exact stent graft placement $(8,9)$. The proximal stent fixation is always close to the coronary ostia and the aortic valve. The distal landing zone can be extended, if there is need for overstenting of the brachiocephalic trunk or even the left carotid artery, by bypassing from the left carotid to the right carotid artery, or even from the left subclavian to the right carotid artery, as in one case with a traumatic rupture of the brachiocephalic trunk that we treated (Figure 1). Obviously, focal lesions, such as ulcers and pseudoaneurysms, as presented in this paper are better to treat comparing to aneurysms or dissections, yet even these procedures carry a relevant morbidity and mortality risk, as seen previously $(10,11)$.

Technical failure in this series was encountered in a patient with PAU who required four endografts, each 45-mm long, and still had a type 3 endoleak at the end of the procedure and during follow-up. Although the authors state that there is no dedicated device available for ascending TEVAR, in fact the Zenith Ascending stent graft (Cook Medical, Denmark) was specifically designed for use in the ascending aorta and can be ordered as a custom made device. This stent is $85 \mathrm{~mm}$ long with bare proximal and distal stents and a $65 \mathrm{~mm}$ covered component. Due to its unique deployment mechanism it can be precisely deployed in the ascending aorta. Furthermore, it carries a soft flexible tip in order to minimize valve trauma. This device was introduced 4 years ago and has been meanwhile implantated $>40$ times for various pathologies of the ascending aorta (personal communication with Cook Medical, Denmark) with promising initial results $(12,13)$.

In summary, the authors of the present report demonstrate not only the feasibility, but also the safety and effectiveness of TEVAR in treating focal lesions of the ascending aorta, yet only in a relative small group of patients. This report, like others, is obviously limited by the limited number of so far treated patients. For this reason, open repair, even in cases of revision surgery, surely remains the gold standard in the management of ascending aortic pathologies. In individual cases with high or even 


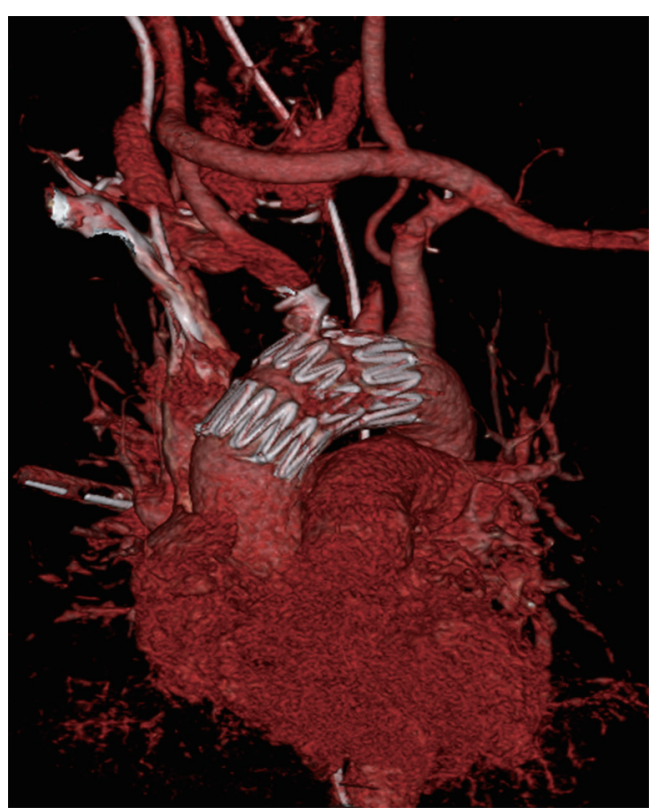

Figure 1 Three-dimensional reconstruction of the postoperative CT-angiography after left subclavian to right carotid bypass with reimplantation of the left carotid artery and TEVAR (Cook Zenith TX2 TBE 42-81) of the proximal aortic arch and vascular plug (Amplatzer II) in a patient with a traumatic rupture of the brachiocephalic trunk. TEVAR, thoracic endovascular aneurysm repair.

prohibitive operative risk endovascular treatment can be considered after multidisciplinary evaluation (among cardiac and vascular surgeons, cardiologists, anesthesiologists), ideally with dedicated stent grafts for the ascending aorta.

\section{Acknowledgements}

None.

\section{Footnote}

Provenance: This is an invited Commentary commissioned by the Section Editor Lei Zhang (Department of Vascular Surgery, Changhai Hospital, Second Military Medical University, Shanghai, China).

Conflicts of Interest: J Kalder is a consultant for Cook Medical, and other authors have no conflicts of interest to declare.

Comment on: Piffaretti G, Galli M, Lomazzi C, et al. Endograft repair for pseudoaneurysms and penetrating ulcers of the ascending aorta. J Thorac Cardiovasc Surg 2016;151:1606-14.

\section{References}

1. Collin J, Murie JA. Endovascular treatment of abdominal aortic aneurysm: a failed experiment. Br J Surg 2001;88:1281-2.

2. United Kingdom EVAR Trial Investigators, Greenhalgh RM, Brown LC, et al. Endovascular versus open repair of abdominal aortic aneurysm. N Engl J Med 2010;362:1863-71.

3. Nienaber CA, Kische S, Rousseau H, et al. Endovascular repair of type $\mathrm{B}$ aortic dissection: long-term results of the randomized investigation of stent grafts in aortic dissection trial. Circ Cardiovasc Interv 2013;6:407-16.

4. Greenberg R, Eagleton M, Mastracci T. Branched endografts for thoracoabdominal aneurysms. J Thorac Cardiovasc Surg 2010;140:S171-8.

5. Haulon S, Greenberg RK, Spear R, et al. Global experience with an inner branched arch endograft. J Thorac Cardiovasc Surg 2014;148:1709-16.

6. Piffaretti G, Galli M, Lomazzi C, et al. Endograft repair for pseudoaneurysms and penetrating ulcers of the ascending aorta. J Thorac Cardiovasc Surg 2016;151:1606-14.

7. Di Eusanio M, Berretta P, Bissoni L, et al. Re-operations on the proximal thoracic aorta: results and predictors of shortand long-term mortality in a series of 174 patients. Eur J Cardiothorac Surg 2011;40:1072-6.

8. Kolvenbach RR, Karmeli R, Pinter LS, et al. Endovascular management of ascending aortic pathology. J Vasc Surg 2011;53:1431-7.

9. Kotelis D, Brenke C, Wörz S, et al. Aortic morphometry at endograft position as assessed by $3 \mathrm{D}$ image analysis affects risk of type I endoleak formation after TEVAR. Langenbecks Arch Surg 2015;400:523-9.

10. Kotelis D, Bischoff MS, Rengier F, et al. Endovascular repair of pseudoaneurysms after open surgery for aortic coarctation. Interact Cardiovasc Thorac Surg 2016;22:26-31.

11. Geisbüsch P, Kotelis D, Weber TF, et al. Early and midterm results after endovascular stent graft repair of penetrating aortic ulcers. J Vasc Surg 2008;48:1361-8.

12. Metcalfe MJ, Karthikesalingam A, Black SA, et al. The first endovascular repair of an acute type A dissection using an endograft designed for the ascending aorta. J Vasc Surg 2012;55:220-2.

13. Tsilimparis N, Debus ES, Oderich GS, et al. International experience with endovascular therapy of the ascending aorta with a dedicated endograft. J Vasc Surg 2016;63:1476-82.

Cite this article as: Kotelis D, Kalder J, Jacobs MJ. Endovascular repair of the ascending aorta: the last frontier? J Thorac Dis 2016;8(8):E825-E826. doi: 10.21037/jtd.2016.07.49 